\title{
A REBEn NO CONTEXTO DA HISTÓRIA DA ENFERMAGEM BRASILEIRA: A IMPORTÂNCIA DA MEMÓRIA DE Da GLETE DE ALCÂNTARA
}

\author{
REBEn (BRAZILIAN JOURNAL OF NURSING) IN THE CONTEXT OF THE BRAZILIAN NURSING: \\ THE IMPORTANCE OF GLETE DE ALCÂNTARA
}

\author{
LA REBEn EN EL CONTEXTO DE LA HISTORIA DE LA ENFERMERÍA BRASILEÑA: \\ LA IMPORTANCIA DE LA MEMORIA DE Da GLETE DE ALCÂNTARA
}

\author{
Isabel Amélia Costa Mendes ${ }^{1}$ \\ Joséte Luzia Leite ${ }^{2}$ \\ Juçara Luzia Leite ${ }^{3}$ \\ Maria Auxiliadora Trevizan ${ }^{1}$
}

\begin{abstract}
RESUMO:O presente trabalho é um estudo de História Social cujo objetivo é recuperar a trajetória profissional de $D^{a}$ Glete de Alcântara junto à Revista Brasileira de Enfermagem /REBEn(inicialmente Anais de Enfermagem), fundamentando-se na concepção de memória de Maurice Halbwachs e no conceito de geração de Daniel Pécaut. Para tanto, foi necessário contextualizar a formação profissional de $D^{a}$ Glete de Alcântara na História da Enfermagem Brasileira, destacando a criação da Escola de Enfermagem de Ribeirão Preto da Universidade de São Paulo(EERP/USP). As fontes utilizadas, analisadas em uma perspectiva histórico-crítica, foram os documentos do Centro de Memória da Escola de Enfermagem de Ribeirão Preto e o acervo da ABEn/Brasilia, sobretudo os Livros de Atas da Associação e os exemplares dos Anais de Enfermagem/ REBEn.
\end{abstract}

PALAVRAS-CHAVE: história da Enfermagem, memória, REBEn, Glete de Alcântara

ABSTRACT: This is a Social History study which aims at recuperating the professional trajectory of Glete de Alcântara in the Revista Brasileira de Enfermagem/ REBEn (Brazilian Journal of Nursing), initially called Anais de Enfermagem. It is based on the concept of memory of Maurice Halbwach, and on the concept of generation of Daniel Pécaut. The study contextualizes the professional development of Glete de Alcântara in the history of the Brazilian nursing, highlighting the creation of the Nursing School of the University of São Paulo (EERP/USP) in Ribeirão Preto. The sources for the study were documents obtained in the Centro de Memória da Escola de Enfermagem (Memory Center of the School of Nursing) of Ribeirão Preto and in ABEN (Brazilian Association of Nursing) in Brasilia. Data obtained in this association were mainly collected from its record books the journals.

Keywords: history of nursing, memory, Revista Brasileira de Enfermagem

RESUMEN: El trabajo es un estudio de Historia Social cuyo objeto es recuperar la trayectoria profesional $D^{a}$ Glete de Alcântara en la Revista Brasileira de Enfermagem /REBEn(inicialmente Anais de Enfermagem) fundamentándonos en el concepto de memoria de Maurice Halbwachs y en el concepto de generación de Daniel Pécaut. Para tanto, ha sido necesario contextualizar la formación profesional de $D^{a}$ Glete de Alcântara en la Historia de la Enfermeria Brasileña, para destacar la creación de la Escola de Enfermagem de Ribeirão Preto da Universidade de São Paulo(EERP/USP). Se han utilizado datos para analizarlos desde una perspectiva histórico-crítica. Son ellos la documentación del Centro de Memória da Escola de Enfermagem de Ribeirão Preto y el acervo de la ABEn/ Brasília, sobre todo los Libros de Actas de la Asociación y los ejemplares de los Anais de Enfermagem/ REBEn.L

PALABRAS CLAVE: historia de la enfermeria, memoria, Revista Brasileira de Enfermagem

Recebido em 31/08/2002

Aprovado em 27/09/2002

\footnotetext{
1 Membros do GEPECOPEn - Grupo de Estudos em Pesquisas em Comunicação no Processo em Comunicação e Enfermagem, Professora Titular da Escola de Enfermagem de Ribeirão Preto da Universidade de São Paulo, Centro Colaborador da OMS para o Desenvolvimento da Pesquisa em Enfermagem.

2 Professora Emérita da UniRio e membro do NUPHEBRAS/EEAN/UFRJ.

${ }^{3}$ Doutora em História Social. Professora Adjunta da UFES, membro do NUPHEBRAS/ EEAN/ UFRJ e membro do GEPECOPEn - EERP/USP
} 


\section{A MEMÓRIA DE UMA GERAÇÃO}

A importância dos estudos históricos em Enfermagem tem-se evidenciado, nas últimas décadas, não apenas pelo crescente número de trabalhos nesse campo, mas também pela necessidade de se repensar a profissão em sua interface com o contexto social em que atua. Já no início da década de 80 do século XX. Trevizan e Mendes(1985), apontavam para a pesquisa em História da Enfermagem como uma das alternativas para o desenvolvimento da profissão. As autoras, nesse trabalho, contextualizaram pensadores com a finalidade de embasarem suas reflexões, atentando para algumas alternativas teóricas que poderiam servir como ponto de partida para as pesquisas na área .

Nesse sentido, considerando a necessidade de esclarecermos nossa fundamentação conceitual, destacamos a importância em nosso estudo do conceito de memória ,conforme o estruturou (HALBWACHS, 1990): uma memória que sempre é coletiva, repensada e reconstruida (posto que sempre que é lembrada é revivida). Assim sendo, compreendemos que recuperar parte da trajetória profissional de $D^{a}$ Glete de Alcântara é reviver a memória de toda uma categoria profissional e, portanto, nossa própria memória, considerando a interferência na realidade do presente em que $o$ ato de rememorar é realizado.

Glete de Alcântara nasceu aos 24 de junho de 1910, em São Sebastião do Paraíso, Minas Gerais. Era a primogênita da família e teve nove irmãos (cinco mulheres e quatro homens). Com a morte de sua mãe, a menina Glete passou a ser responsável pela educação de seus irmãos menores : isso marcou a sua vida que tendeu mais para o lado profissional que para o lado pessoal. Não obstante, ou talvez por isso mesmo, a dimensão afetiva ocupou grande espaço em sua trajetória profissional, conforme narram diversas depoentes.(ANGERAMI ;PELÁ,1974)

Sua infância transcorreu, portanto, sob os ideais de uma jovem República que investia na consolidação de uma identidade nacional, de uma educação que visava a construção de cidadãos que haviam recentemente deixado de ser súditos, e de uma nova concepção de trabalho.

Lembramos que, desde o início da República, o eixo central do curriculo das escolas já havia migrado das humanidades para as ciências naturais, enfatizando tarefas como a descrição e a observação, com grande influência das idéias positivistas. A menina Glete, e toda uma geração de mulheres que se educaram no Brasil da época, não podia ficar alheia ao contexto no qual crescera e solidificara seu espírito intelectual, dai seu marcante ecletismo e apego às formas diversas de manifestações culturais. Dai também sua opção pela Enfermagem e sua interface com as Ciências Sociais, e a relação de sua trajetória profissional com a História da Enfermagem no Brasil, sobretudo em São Paulo (ela licenciou-se em Ciências Sociais em 1951, pela USP, e obteve o título de "Mestre em Currículo e Ensino de Escolas de Enfermagem" na Universidade de Columbia - EUA - , em 1950).

\section{A REBEn E A EXPANSÃO DA ENFERMAGEM NO BRASIL}

Em consonância com o quadro de expansão das
Escolas de Enfermagem no país, a criação de uma Escola de Enfermagem na Universidade de São Paulo havia sido uma das condições impostas pela Fundação Rockefeller quando assumiu o compromisso de financiar as novas instalações dos laboratórios do novo prédio da Faculdade de Medicina. Miss Mary Elizabeth Tennant, representante daquela Fundação, chegou ao Brasil para cobrar o cumprimento dessa condição e para conceder seis bolsas de estudos a fim de que enfermeiras se preparassem no exterior para a atividade acadêmica. Em 1940, seguiram para os EUA Da Zilda de Almeida Carvalho e $D^{\text {a }}$ Maria Rosa de Sousa Pinheiro. No ano seguinte, foi a vez de $D^{a}$ Glete de Alcântara e de $D^{\mathrm{a}}$ Lúcia Jardim, seguirem para Toronto, no Canadá, lá ficando até quase o final da $2^{\mathrm{a}}$ Guerra.

Em 1944, ao retornar para o Brasil, Da Glete passou a ensinar "Arte de Enfermagem" na Escola de Enfermagem da Universidade de São Paulo. Apesar de nunca ter pertencido ao quadro do Hospital das Clínicas, assumiu a chefia de uma das unidades de internação, posto que era professora da Escola. Com o final da $2^{\mathrm{a}}$ Guerra, foi necessário e urgente que se repensasse o status da profissão e da formação em Enfermagem, e foi nesse contexto que, juntamente com o processo de reorganização da Associação Brasileira de Enfermagem Diplomadas ABED, em 1945/46, o periódico Anais de Enfermagem passou a ser editado e publicado trimestralmente em São Paulo. Não sem razão, após a festa de Santo Antônio realizada na Escola de Enfermagem da USP aos 12 de junho de 1946, cuja arrecadação fora em benefício dos Anais de Enfermagem, foi solicitado que fosse "lançado em ata um voto de louvor a Glete de Alcântara, pela sua cooperação em Anais de Enfermagem (CARVALHO,1976).

Publicado pela ABED no Rio de Janeiro desde 1932, e criado sob a direção de Rachel Haddock Lobo, os Anais de Enfermagem mantiveram seus objetivos iniciais: a atualização dos estudos de Educação e Enfermagem, de Serviços de Enfermagem e de Tratamentos, além de servir como meio de comunicação entre os dispersos grupos de enfermeiras no território nacional. Constituiu-se, assim, no mais importante ambiente de sociabilidade intelectual da categoria e, por isso, não podemos dissociar a trajetória deste periódico da própria História da Enfermagem no Brasil.

No entanto, devido às diversas dificuldades do periodo, sobretudo de ordem financeira, a publicação do periódico foi suspensa em 1941, após o n 17. O primeiro número, após a transferência para São Paulo, saiu em março de 1946 ( $\left.n^{\circ} 18\right)$, com a seguinte reveladora nota:

A arte da Enfermagem é a mais bela das artes e, considerada como tal, requer pelo menos tão delicado aprendizado quanto a pintura ou a escultura, pois que não pode haver comparação entre o trabalho de quem se aplica à tela morta ou ao mármore frio, com o de quem se consagra ao corpo vivo. O cuidar de doentes é tarefa que sempre coube à mulher e sempre lhe deve caber. (ANAIS DE ENFERMAGEM, 1946, p. 8).

Além da alteração dos responsáveis pela publicação, também houve mudanças no planejamento gráfico da revista. Na ocasião, a Redatora Chefe da publicação era $D^{a}$ Edith de Magalhães Fraenkel, tendo como secretária $D^{a}$ Marina Bandeira de Melo, como tesoureira Da Safira Gomes Pereira, e como editor o Sr. José Maria Machado. No entanto, 
a partir de 1947, ano do $1^{\circ}$. Congresso Nacional de Enfermagem, Da Glete de Alcântara passou a atuar como secretária da revista. Desde essa data até o seu falecimento, em 1974, Da Glete de Alcântara não deixou de trabalhar para a revista, nem para a Associação.

$01^{\circ}$. Congresso Nacional de Enfermagem, realizado em São Paulo no periodo de 17 a 22 de março de 1947, foi um marco para a Enfermagem brasileira e o inicio de uma série que consolidou um novo ambiente intelectual da Enfermagem e áreas afins no Brasil. Em seu cartaz de divulgação, a Comissão Organizadora deixara clara a intenção do evento: "Elaborar, em conjunto, um programa eficiente de enfermagem, visando o desenvolvimento da profissão num plano elevado". Na ocasião, Da Glete era presidente da Comissão dos Anais de Enfermagem e, no Livro de Atas do Congresso, encontramos o seguinte registro: "Com a palavra a Presidente da Comissão dos Anais de Enfermagem, Sra. Glete de Alcântara, que procedeu à leitura de seu relatório, o qual, posto em discussão, foi aprovado e anexado à ata (...)" (ABED, 1947, não paginada).

Em junho daquele mesmo ano, Da Glete publicou Cuidados de Enfermagem ao Paciente com Úlcera GastroDuodena (ALCÂNTARA, 1947). Nesse trabalho, analisou os cuidados de enfermagem enfocando os seguintes itens: observação dos sintomas, repouso, medicação, dieta, psicoterapia, higiene e educação do paciente, revelando que sua concepção de Enfermagem transcendia o momento imediato do "cuidar". Era o inicio, no Brasil, de sua vasta obra escrita e de seu processo ininterrupto de dedicação à pesquisa em Enfermagem.

Em 1948, ainda Secretária dos Anais e eleita para a presidência da $A B E D$ da regional de São Paulo (cargo que ocupou até 1951), Da Glete assumiu, ao lado de $D^{a}$ Edith Fraenkel, a Divisão de Educação da ABED. Reconhecia, assim, a oportunidade de se reconsiderar o curriculo da Enfermagem, incorporando idéias trazidas de seus estudos em Ciências Sociais e de seu compromisso com a Educação.

Uma nova fase se iniciou para os Anais de Enfermagem, tendo sido adotada uma nova seriação. Assim, no volume 1, n. 1, da "nova" revista, foi publicada a seguinte Nota da Redação:

Pela quarta vez em sua curta existência, esta revista muda de formato, e, se alguém possuir a coleção, do seu inicio até a interrupção em 1941, verificará que o presente número muito se assemelha àqueles publicados em 1935 em diante. As causas que determinaram as modificações anteriores são por nós desconhecidas, mas,esta última alteração foi motivada por argumentos sérios apresentados pela atual casa editora, de que um trabalho econômico e bem feito implicaria na diminuição do formato. (...). (ANAIS DE ENFERMAGEM, 1948, p. 1).

A respeito dessa fase dos Anais de Enfermagem, a própria $D^{a}$ Glete de Alcântara escreveria, anos mais tarde, a seguinte reflexão:

As alterações sofridas não se verificaram somente na redução do formato para tornar menos dispendioso seu custo. Procurou-se, de um lado, elevar o nivel do conteúdo da publicação, pela seleção mais rigorosa dos trabalhos, e de outro, estimular a produção de literatura profissional pelas próprias enfermeiras. Como órgão de classe, Anais de Enfermagem precisa refletir o desenvolvimento profissional através de maior contribuição das próprias enfermeiras. Os números publicados nos primeiros tempos, após a mudança ocorrida, não revelaram as alterações profundas que se desejava imprimir.(CARVALHO, 1976, p.340).

É importante ressaltar que a questão do formato da revista estava presente em muitas situações, sobretudo no que dizia respeito à publicação ou não de anúncios publicitários. Tais discussões estavam diretamente ligadas à questão da sobrevivência financeira da revista, que não conseguia autonomia apenas com a arrecadação de assinaturas. $D^{a}$ Glete, na qualidade de Presidente da Comissão dos Anais de Enfermagem e Secretária da publicação, juntamente com Da Edith Fraenkel, Redatora Chefe, se empenharam em campanhas de sensibilização das enfermeiras para a assinatura da revista durante as décadas seguintes, conforme depreendemos a partir do seguinte trecho:

(...) A Sra. Presidente passa a palavra para a Redatora Chefe dos Anais de Enfermagem que fez a leitura do relatório da Presidente da Comissão de Anais de Enfermagem os quais são aprovados pela Assembléia. Após a leitura de seu relatório, a Redatora Chefe fez um apelo às sócias pedindo trabalhos para a revista e que estas se interessem em conseguir mais assinantes, uma vez que o dinheiro existente em caixa não cobre as despesas para as edições em 1948: A presidente agradece à Sra. Redatora Chefe, D. Edith Fraenkel, a colaboração trazida à Associação estendendo estes agradecimentos às alunas da Escola de Enfermagem de São Paulo, que muito têm colaborado com a redação da referida revista e organizando festas para angariar fundos para suas tiragens. (...) (ABED, 1947, não paginada).

Apesar do empenho e preocupação de todas as associadas, o número de assinaturas dos Anais de Enfermagem continuou a ser um problema pra a ABED. Em 1952, a presidente da ABED, D. Waleska Paixão, observou que mais de 300 assinaturas não haviam sido renovadas, fato lamentado por $D^{a}$ Glete de Alcântara ao lembrar que a questão da remessa dos exemplares às assinantes era um problema que precisava ser resolvido e um dos fatores que mais contribuíram para a não renovação das assinaturas. (ABED, 1957, p. 130). No mesmo ano, Da Glete foi eleita presidente da ABED nacional, cargo no qual permaneceu até 1954. Na transição de sua gestão para a de $D^{a}$ Maria Rosa Souza Pinheiro, durante o VII Congresso Nacional de Enfermagem, os Anais de Enfermagem mudaram seu nome para Revista Brasileira de Enfermagem (REBEn), juntamente com a alteração para Associação Brasileira de Enfermagem (ABEn). (ABED, 1954, não paginada).

O novo nome foi uma estratégia para adequar a publicação e a Associação à realidade da Enfermagem brasileira: uma outra geração de enfermeiras estava na gestão da Associação e das Escolas, influenciadas pelo contexto de um mundo pós-guerra e pelo "nacionaldesenvolvimentismo" no pais, o que marcou a criação de novos espaços acadêmicos, como a Escola de Enfermagem de Ribeirão Preto da Universidade de São Paulo (EERP/ USP), cujo primeiro vestibular foi realizado em 1953. Neste caso especifico, sob a liderança de Da Glete de Alcântara, as principais inovações se relacionavam a uma maior 
contribuição da Escola para os serviços do setor de Enfermagem em Ribeirão Preto, uma vez que, a partir de pesquisas quanti-qualitativas: percebeu que a maioria do pessoal auxiliar não possuía sequer o primário completo; levantou a opinião da comunidade em relação à figura da enfermeira; e lançou campanhas de esclarecimento junto à população em geral sobre a profissão e o "novo tipo de enfermeira que a Escola pretendia formar", utilizando-se de modernas técnicas de comunicação (projeção de filmes e slides, sobretudo nas escolas secundárias). Outra caracteristica imposta por $D^{\text {a }}$ Glete à EERP foi a importância dada ao cuidado do paciente e aos aspectos educativos e psico-sociais (idéias de ensino-aprendizagem e de autoavaliação), além de incentivar o estudo de línguas estrangeiras (dando ela própria aulas de inglês), e de introduzir grupos de leitura e atualizações bibliográficas estimulando a participação em eventos científicos. Segundo ela:

A enfermagem, como função social, exerce certa força, ao mesmo tempo que sofre a ação de outras forças sociais. Sob este ponto de vista, uma escola de enfermagem integrada numa sociedade irá exercer influência sobre outras instituições sociais, contribuindo para uma mudança dos padrões de comportamento e de atitudes, favorável à promoção da saúde e à prevenção da doença (ALCÂNTARA, 1952,p.311)

Lembramos que a REBEn (Anais de Enfermagem) e a realização dos Congressos Nacionais foram os únicos ambientes intelectuais para a discussão e socialização das pesquisas em Enfermagem por diversas gerações tendo a pós-graduação na área se iniciado e se consolidado apenas na década de 70 do século XX. A importância da publicação e dos eventos científicos, bem como da atuação da Associação para as reflexões sobre a Enfermagem e a enfermeira não pode, portanto, ser questionada, tampouco o empenho das gerações passadas. Esclarecemos que o conceito de geração que empregamos neste trabalho está baseado em Pécaut (1990) como um grupo que partilha uma "solidariedade de idade", mas que não se reduz a isso, posto que partilha também de uma determinada produção intelectual em um determinado periodo do contexto nacional. Da Glete de Alcântara, em 1963, apresentou, em Ribeirão Preto, sua tese de cátedra intitulada "A Enfermagem Moderna como Categoria Profissional: Obstáculos à sua Expansão na Sociedade Brasileira", onde registrou, mais uma vez, sua preocupação com as questões intrinsecas à formação da enfermeira e a sua profissão. Faleceu em 1974, no final de seu $2^{\circ}$ mandato como presidente na ABEn Nacional, tendo lançado, no pais, as bases da consolidação do reconhecimento da Enfermagem em sua perspectiva científica, para além dos preconceitos existentes. Consideramos, portanto, que a identidade da profissão passou pela trajetória profissional de $D^{a}$ Glete, que atuou na Associação, nos Congressos, na Academia, na Comunidade e na REBEn.

\section{A REBEn E OS ESTUDOS SOBRE A HISTÓRIA DA ENFERMAGEM}

Concluímos que a concepção de Enfermagem inicialmente identificada nas mentalidades, vem mudando lentamente, graças aos esforços e à liderança de profissionais como $D^{a}$ Glete de Alcântara. O número crescente de Escolas de Enfermagem, a melhor preparação das enfermeiras para ensinar e administrar, além da expansão dos serviços de saúde, podem também ser atribuídos à disseminação de uma literatura profissional, papel que vem sendo desempenhado pela REBEn. A história desse periódico não pode ser dissociada, portanto, da própria História da Enfermagem e do país. Como diria a própria Da. Glete, em seu "Brief Review of Nursing in Brazil: a Enfermagem como uma instituição social reflete o desenvolvimento deste país como um todo."

\section{REFERÊNCIAS BIBLIOGRÁFICAS}

ALCÂNTARA, G. Enfermagem Médica: cuidados de enfermagem ao paciente com úlcera gastro-duodenal. Anais de Enfermagem., São Paulo, n.23, p. 15-17, jun. 1947.

Currículo de Escolas de Enfermagem: integração da Escola de Enfermagem na sociedade. Anais de Enfermagem., São Paulo, v. 5, n. 4, p. 311-319, 1952.

$\overline{\mathrm{MEC}, 1957 .}$

Brief Review of Nursing in Brazil. Rio de Janeiro:

A Enfermagem Moderna como Categoria Profissional: obstáculos à sua expansão na sociedade brasileira. 1963.117f. Tese (Cátedra) - Escola de Enfermagem de RibeirãoPreto, Universidade de São Paulo, Ribeirão Preto.

ALCÂNTARA, G.; FORJAZ, M. V. O Ensino de Ética nas Escolas de Enfermagem. Revista Brasileira de Enfermagem., São Paulo, p. 193-233, jun. 1961.

ANAIS DE ENFERMAGEM. Nota da Redação. Anais de Enfermagem, Rio de Janeiro, v. 18, jan./mar. 1946.

ANAIS DE ENFERMAGEM. Nota da redação. Anais de Enfermagem, Rio de Janeiro, v. 1, n. 1, mar. 1948.

ANGERAMI, E. L. S. ; PELÁ, N. T. R. (Orgs). Glete de Alcântara: Vida e Obra. São Paulo: ABEn, 1974.

ASSOCIAÇÃO BRASILEIRA DE ENFERMAGEM. Conselho Deliberativo. Ata da reunião realizada em 20 de jul. de 1957. v. II, p. 130. Arquivo da ABEn Nacional.

ASSOCIAÇÃO BRASILEIRA DE ENFERMEIRAS DIPLOMADAS. Assembléia Geral. Ata da assembléia realizada em 18 de nov. de 1947. v. II. Não paginada. Arquivo da ABEn Nacional.

ASSOCIAÇÃO BRASILEIRA DE ENFERMEIRAS DIPLOMADA. Assembléia Geral. Ata da assembléia realizada em 21 ago. 1954. v. III. Arquivo da ABEn Nacional.

ASSOCIAÇÃO BRASILEIRA DE ENFERMEIRAS DIPLOMADA. Congresso Nacional de Enfermagem. Ata da sessão realizada em 17 de mar. de 1947. Livro 29. Arquivo da ABEn Nacional

CARVALHO, A. C. Associação Brasileira de Enfermagem (1926 - 1976): Documentário. Rio de Janeiro: ABEn, 1976. 
A REBEn no contexto da história...

HALBWACHS, M. A memória coletiva. São Paulo: Vértice, 1990.

LEITE, J. L.; LEITE, J. Enfermeiras Militares Brasileiras: a luta por trás da Guerra. Revista da Associação Portuguesa de Enfermeiros, Lisboa, $2^{\mathrm{a}}$ série, p. 32-36, abr./ jun. 2001.
PECAUT, D. Os intelectuais e a política brasileira entre o povo e a nação. São Paulo: Ática, 1990.

TREVIZAN, M. A.; MENDES, I. A. C. A Pesquisa Histórica como necessidade na Enfermagem. Revista Gaúcha de Enfermagem, Porto Alegre, p. 27-34, 1985. 